\title{
The Cognitive Neuropsychology of Depression in Adolescents
}

\author{
Abigail Oliver $^{1} \cdot$ Victoria Pile $^{1} \cdot$ Deborah Elm $^{1} \cdot$ Jennifer Y. F. Lau ${ }^{1}$
}

Published online: 16 September 2019

(C) The Author(s) 2019

\begin{abstract}
Purpose of Review Adolescent depression is a major public health concern associated with severe outcomes. A lack of efficacious interventions has triggered an increase in cognitive neuropsychology research to identify relevant treatment targets for new interventions. This review summarises key neurocognitive findings in adolescent depression and explores the potential of neurocognitive markers as treatment targets in new interventions.

Recent Findings Studies support difficulties in the voluntary deployment of attention towards and away from emotional stimuli, negative interpretation biases and overgeneralised autobiographical memories in adolescent depression; however, little evidence is given to a general decline in executive function. There is consistent evidence for abnormalities in several distributed neural networks in adolescent depression, including dysfunction in and between the amygdala, medial prefrontal cortex and ventral striatum.

Summary The relationships between different cognitive biases and abnormalities in specific neural networks remain unclear. Several new experimental interventions targeting these neurocognitive markers await evaluation.
\end{abstract}

Keywords Adolescent depression · Cognitive neuropsychology $\cdot$ Information processing $\cdot$ Cognitive bias $\cdot$ Executive function · Neural dysfunction

\section{Introduction}

Depression is a major public health concern and leading cause of morbidity worldwide [1]. Many cases of depression start in youth [2], which may be associated with greater illness burden than depression starting in adulthood [3]; effects include poor social relationships and networks, low educational attainment, unstable employment, further serious mental health problems and suicide $[4,5]$. Due to concerns that the prevalence of depression is rising in this young age group [6] and a consistent failure to produce well-replicated efficacious treatments in adolescent depression [7], a growing research focus has been on elucidating neurocognitive markers of adolescent depression and their potential as treatment targets in new interventions. Here, we review

This article is part of the Topical Collection on Mood and Anxiety Disorders

Jennifer Y. F. Lau

jennifer.lau@kcl.ac.uk

1 Institute of Psychiatry, Psychology and Neuroscience, King's College London, London, UK maladaptive patterns of information processing and associated patterns of neural dysfunction found to characterise adolescent depression. We evaluate the potential of these as risk markers and conclude by briefly considering their potential as treatment targets in the development (and evaluation) of novel early interventions.

\section{Maladaptive Patterns of Information Processing in Youths with Depression}

Cognitive theories propose that depression is influenced by thoughts, attitudes and the way information is attended to, interpreted and remembered. The way information is processed can influence emotional responses; thus, biased processing of emotional material ("cognitive biases") and difficulties processing non-emotional information ("poor cognitive control") may maintain depression and increase the risk for developing symptoms in vulnerable groups. Studies have measured depression-linked biases in attention, interpretation and memory of emotional (including self-referential/autobiographical) materials, and problematic cognitive processing of non-emotional and emotional materials. 


\section{Attention Biases for Negative over Positive Materials}

Attention biases refer to the preferential allocation of attention towards (or away) from negative over non-negative stimuli. As an increased focus on negative over positive materials can magnify perceived negativity in the environment, this maladaptive style of processing could maintain and influence depressive affect. Studies have reported a selective bias for negative and/or unpleasant stimuli among depressed youth [8], particularly when these stimuli are presented for long durations. However, studies of community youth have reported more mixed findings. Some studies have found a relationship between negative attention bias for negative faces and depressive symptoms [9], whereas others have found no relationship [10] or the relationship is better explained by anxiety [11]. Still, other studies have only found associations when a third variable is taken into account, such as genotype [12] or low (not high) effortful control (indicator of poor executive control) [13]. A few studies have measured attention biases away from positive materials: one study tracked participants' eye movements whilst passively viewing emotional faces, finding that unlike adults with depression, depressed youth spent longer attending to happy compared with sad faces [14].

Studies investigating whether attention biases are a vulnerability factor for depression have found conflicting results. In studies of non-depressed children of depressed mothers (compared with never depressed mothers), two studies found an attention bias towards sad faces $[15,16]$ whilst two others found attentional avoidance of sad faces [17, 18] but these latter effects were moderated by high suppression [17] and serotonin transporter genotype [18]. Additionally, a study that investigated attention bias in the mother and child showed that youth of depressed (or anxious) mothers manifested a negative attention bias to negative stimuli if the mothers showed reduced attention bias to positive information (relative to controls) [19].

\section{Interpretation Biases}

Interpretation biases refer to a tendency to draw negative inferences, causes or outcomes from ambiguous cues. Depressed youth select more negative meanings of words in homophone/homograph tasks [20] and endorse more negative interpretations and fewer positive interpretations of ambiguous information relative to controls [21,22]. Interpretation biases also show a positive correlation with depressive symptom severity $[11,20,22,23]$. However, given the high cooccurrence of anxiety within depressed individuals, and findings of an association between anxiety and biased threat interpretations [24], anxiety may account for the findings: one study suggested that the relationship between interpretation biases and depression is independent of anxiety [20], whereas another suggested the opposite [11].
There is initial evidence that interpretation bias may increase risk for depression. One study found that interpretation biases predicted increased depression symptoms 4-6 weeks later in a student sample [25], whilst another reported negative interpretation biases in daughters of depressed mothers [26]. Moreover, among maltreated young adults, those with greater negative interpretation bias were more likely to experience symptoms of depression [27].

\section{Memory Biases}

Depression may be associated with enhanced recall of negative material, reduced recall of positive including autobiographical material and overgeneral memory. Research in youth depression is mixed in relation to the enhanced recall of negative material [28]. Early studies have reported group differences between depressed and non-depressed youth in enhanced recall of negative compared with positive selfreferent adjectives $[29,30]$. However, other studies have not replicated (or only partly replicated) this finding in patients versus controls [31,32], or in currently, previously and never depressed youth following a negative mood induction [33]. Mixed results have also been found among community youth. One study found no evidence of an association between negative words and depressive symptoms [11] whilst two other studies reported that enhanced recall of negative stories [34] or reduced recall of positive material was associated with depressive symptoms [35]. In terms of whether memory biases for self-referent words represent a risk factor for depression, one study assessed this bias in daughters of depressed mothers [36]. They found no negative memory bias in daughters of depressed versus non-depressed mothers unless the COMT Val158Met polymorphism was taken into account, which plays a key role in regulating pre-frontal dopamine activity.

Autobiographical memory relates to the ability to recollect facts and personal events from one's life [37]. Overgeneral memory (OGM) is a phenomenon where individuals have difficulty retrieving specific autobiographical memories and instead generate categorical or extended memories. A recent review of 17 articles concluded that OGM predicts depression in young people [38•] with moderate-to-large effect sizes [39, 40]. There has also been some investigation of whether OGM marks risk for depression. In females with elevated symptoms of depression, OGM predicted depression a year later [41]. Moreover, in 10- to 18-year-old healthy girls at familial risk of depression, OGM predicted depression 1 year later [40]. Many studies also support a relationship between trauma exposure (a risk factor for adolescent depression) and OGM in young people with moderate-to-large effect sizes, across a range of trauma types [42-44]. 


\section{Executive Function and Cognitive Control Difficulties}

Higher order neurocognitive processes, notably executive function (EF), which encompasses working memory, attention flexibility and inhibitory control, are important for goaldirected behaviour-cognitive control. These executive processes develop throughout childhood and adolescence [45] and have been linked to depression [46] as underpinning associated patterns of information processing biases. Research investigating executive functioning in depressed youth has been mixed. A recent review concluded that there is little support for deficits in EF [47•], in particular in response inhibition, attentional set shifting, selective attention, verbal working memory and verbal fluency. More studies were needed to investigate potential deficits in spatial working memory processing, sustaining attention, planning and decision-making. Given links between these cognitive deficits with the chronicity (number of episodes), age and severity of depression in adults, it is unsurprising that research is mixed in youth where depression is likely to be part of a first episode. For example, difficulties on the Wisconsin Card Sort Task (measures setshifting - ability to flexibly shift in response to changing schedules of reinforcement) are found for groups with major but not minor depression [48]. A large community study examined the relationship between neurocognitive functioning and affective symptoms [49]. Longitudinally, only response inhibition scores in girls at baseline predicted affective difficulties at a 5 -year but not 2.5-year follow-up. The authors suggested that it might be a prodromal factor linked to late rather than early-onset depression.

Some studies have measured executive function during the presentation of emotional stimuli, so-called hot cognitive control tasks. Under emotional task conditions, depressed youths are more likely to allocate attention to negative stimuli (compared with controls), thus affecting task performance [50-52, although see: 22].

\section{Summary}

Whilst data in youth are fewer, depression-linked effects in youth are reasonably consistent with adult findings, with some notable exceptions, which could be due to authentic developmental differences or artefacts of the extension of adult methodologies to adolescent samples. It would perhaps be more informative to create new paradigms for adolescent samples, considering the task instructions and parameters in the context of cognitive development and/or the use of emotional stimuli that are more salient for young people, such as peer relationships. Drawing across studies of attention biases suggests difficulties in the voluntary (and flexible) deployment of attention towards and away from emotional stimuli. There also appears to be robust evidence for biases in interpretation and OGM. Most evidence implies that there is not a general deficit in $\mathrm{EF}$ in adolescent depression. Whether biases in attention and interpretation represent cognitive markers of risk for adolescent depression need further empirical investigation. However, there is more robust data suggesting that individuals at-risk for depression because of an early life adversity show overgeneral memories.

\section{Brain Circuitry Dysfunctions in Youth with Depression}

Data from adults suggests that depression-linked maladaptive information processing patterns may co-occur/arise from brain circuitry dysfunctions [53, 54]. However, it is important to establish these associations independently in adolescence, given the protracted maturation of neural regions involved in higher-level cognition, namely an increased surface area of the cortex $[55,56]$ during this juncture. Such developmental changes could alter the relationship between brain circuits, information processing and symptoms of depression. Because of their capacity to more precisely map the spatial correlates of activation in response to stimuli and performance demands presented across a time series, functional MRI (fMRI) methods have been used to infer patterns of brain circuit dysfunction in youth depression (and those at-risk for depression). Two reviews of fMRI studies conducted in youth with depression have been published recently $[57 \bullet \bullet, 58 \bullet \bullet]$. The first used a systematic search to identify 20 fMRI studies of emotion processing, affective cognition, reward processing and cognitive control; performing a quantitative analysis of effect sizes of between-group differences across tasks, the authors reported robust functional differences in the ventromedial prefrontal cortex (vmPFC), including orbitofrontal cortex (OFC), and amygdala, with differences in the dorsolateral prefrontal cortex (dIPFC) also emerging. In the second, a meta-analysis of whole-brain between-group differences across 14 studies of affective processing and executive function, Miller and colleagues (2015) reported that depressed youth showed hyperactivation in left dlPFC, left subgenual anterior cingulate cortex (ACC), right anterior insula, bilateral thalamus, left parahippocampal gyrus, and left superior temporal cortex as well as hypoactivity within the right caudate, compared with those without a history of depression [58••]. Whilst across these reviews, dysfunctions in several distributed brain networks are suggested during information processing, it is more interesting to examine neural dysfunctions that emerge to specific stimuli, or whilst performing a particular cognitive task. Furthermore, since these two reviews, more studies that assess patterns of neural activation during specific cognitive-affective tasks have been conducted. To better interpret these findings, we divide studies into those that probe neural anomalies during emotion processing, emotion 
regulation, reward processing and executive function or cognitive control tasks.

\section{Neural Abnormalities during Emotion Processing}

fMRI studies of emotion processing are those in which emotional, usually negative stimuli such as fearful or sad faces are presented, aiming to probe involuntary responses to these stimuli relative to neutral stimuli. Across their review, Kerestes and colleagues (2014) reported consistent evidence of hyperactivity in the amygdala and altered connectivity between the amygdala and ACC among youth with depression [57••]. Somewhat deviating from these findings, Miller and colleagues (2015) found group differences within the left dlPFC, bilateral thalamus and left parahippocampal gyrus emerged during affective processing (although they also included studies examining positive emotions) [58・•]. Other studies have also underscored altered amygdala activity in association with youth depression; one study reported that adolescent depression was associated with increased amygdala activity to negative facial expressions, compared with healthy controls [59] whilst another reported a positive relationship between amygdala reactivity to sad faces (but not happy, fearful or neutral) and depression symptom severity [60]. In contrast, studies utilising more explicit methods to tap emotional responses (e.g. labelling) have not reported significant depression-linked differences in amygdala reactivity $[60,61]$. In terms of ACC findings, two recent studies found that compared with healthy controls, depressed adolescents had reduced reactivity in the left and subgenual ACC to threat faces $[62,63]$. However, a third showed increased activation of the medial prefrontal cortex (mPFC) and posterior cingulate cortex (PCC) during emotion processing in depressed adolescents compared with healthy controls [64]. Two studies have investigated functional connectivity (FC) between the amygdala and ACC during emotion processing. Depressed youth had significantly higher FC between the mPFC and the left amygdala than healthy controls, particularly whilst viewing sad faces [63, 64].

A handful of studies have examined amygdala reactivity in adolescents at high or low familial risk for depression. Two studies found that fear faces elicited higher bilateral amygdala activity among high-risk participants compared with low-risk participants, independent of current depression [65, 66•]. However, Burkhouse and colleagues (2017) did not replicate these group differences in their high- and low-risk sample [67]. In the Swartz et al. (2014) study, left amygdala reactivity to threat in the high-risk group also showed complex interactions with age and life stress [66॰]. Although no significant differences in ACC reactivity to threat faces have been found between high-risk and low-risk adolescents [65], reduced ACC activity among high-risk adolescents has emerged in response to happy faces.
Neural Abnormalities during Emotion Regulation

fMRI studies of emotion regulation are those using tasks that assess the cognitive regulation of emotion including involuntary and voluntary processes. Similar to the findings of emotion processing, Kerestes and colleagues (2014) found that studies they termed "affective cognition" reported elevated amygdala activation in depressed youth with preliminary evidence of altered connectivity with the mPFC [57••]. Since this review, a handful of studies have investigated neural activity during cognitive reappraisal. Findings have been mixed for group differences in amygdala involvement during cognitive reappraisal. Three recent studies found no significant group differences in amygdala activity [68-70], although one of these [68] did find that depression symptom severity correlated significantly with reduced amygdala activity during reappraisal of sad faces compared with passive viewing. In contrast, Stephanou and colleagues (2017) found that adolescent depression was associated with a significantly reduced ability to decrease negative affect during reappraisal compared with controls, which corresponded to reduced regulation of amygdala activity [71]. These studies have also investigated differences in prefrontal regions: two studies reported no significant differences in prefrontal activity $[69,70]$ whilst a further two demonstrated prefrontal (vmPFC, left inferior frontal gyrus) hyperactivity in adolescent depression compared with healthy controls $[68,71]$. In terms of FC, connectivity between frontal regions (including the dorsomedial PFC, dIPFC, left ACC, subgenual ACC) and the insula and amygdala was reduced in depressed youth compared with healthy controls during cognitive reappraisal $[69,72]$. However, Platt and colleagues (2015) found increased FC during reappraisal between the right frontal pole and multiple neural regions, including the cerebellum, fusiform gyrus and bilateral amygdala [70].

\section{Neural Abnormalities during Reward Processing}

Studies of reward processing are those that measure the selection, anticipation and consumption phases of monetary and social reward. In the systematic review by Kerestes and colleagues (2014), reasonably consistent findings of diminished striatal activation during reward anticipation and outcome were found with some data also suggesting reduced activation in the ACC and OFC [57••]. Consistent with this, a recent study investigating a sample of female adolescents found that activity in the ventral striatum during reward anticipation decreased in a graded manner from healthy controls to individuals with current subthreshold depression, and individuals with current clinical depression [73]. Similar findings have been reported during reward outcome: ventral striatum reactivity was negatively correlated with depression severity in a clinical adolescent sample [74]. Some studies [75] have also 
found reduced activity in the pregenual ACC during anticipation of rewards in adolescents with high levels of depressive symptomology, compared with those with lower levels. Jin and colleagues (2017) also found that reduced activity in the OFC during reward outcome was associated with increased depressive symptoms [76]. Finally, boys with a history of depression showed heightened positive connectivity between the nucleus accumbens (part of the ventral striatum) and the $\mathrm{mPFC}$ relative to boys with no psychiatric history during reward outcome [77]. This increased frontostriatal connectivity was also associated with a greater number of depressive episodes in the boys' lifetime.

Some of these neural patterns have been found to predict subthreshold or clinical depression across time; Stringaris and colleagues reported that reduced striatal reward anticipation was associated with symptoms 2 years later [73] whilst Jin and colleagues (2017) showed that reduced OFC responses predicted depressive symptoms 9 months later [76]. Among individuals of high familial risk, there was a noted absence of significant ventral striatum activation during reward anticipation and outcome in one study [78]. Olino and colleagues (2014) also found ventral striatum hypoactivity in high-risk adolescents during reward anticipation and outcome, compared with low-risk participants. Controlling for youth selfreported depression, familial risk continued to be associated with ventral striatum activity during reward anticipation but not outcome [79]. However, in contrast to these findings of striatal hypoactivity, one study has reported that high familial risk adolescents showed longitudinal increases in ventral striatum and dIPFC activity to rewards during risk-taking [80].

\section{Neural Abnormalities during Executive Function (Cognitive Control) Tasks}

fMRI studies of executive function in adolescent depression have usually probed selective and sustained attention and/or response inhibition. In the Kerestes et al. (2014) systematic review, different neural correlates were identified for these two types of task: whilst studies probing attention reported altered fronto-cingulate activation (in dorsolateral and ventrolateral PFC), studies measuring neural activations during response inhibition tasks reported altered ACC activation and co-activation with vmPFC [57••]. In contrast, in the metaanalysis performed by Miller and colleagues (2015), depression-linked differences in the right dorsal cingulate cortex, right dorsal anterior insula and left cuneus emerged [58 • $]$. Recently, Diler and colleagues (2014) found that depressed adolescents had significantly higher activity in the left superior temporal gyrus and left caudate during response inhibition, compared with controls [81]. In comparison, Ho and colleagues (2017) found that, compared with healthy controls, depressed adolescents had limited changes in FC between resting state and during a response inhibition task (inflexible
FC). This inflexible FC was found between the right dorsal ACC and the medial frontal gyrus significantly predicted reduced performance during the response inhibition task [82].

Using emotional versions of these inhibitory tasks, one study found that during sad inhibition trials, there were significant effects of group (depression vs healthy controls) and sex on neural activity. Male adolescents with depression demonstrated significantly reduced activity in the supramarginal gyrus, PCC and cerebellum compared with healthy controls [83] but no significant activation differences were observed during happy inhibition trials. In addition, Colich, Foland-Ross, Eggleston, Singh and Gotlib (2016) found that adolescents with depression had decreased activity in the right dlPFC and in the bilateral occipital cortex to sad inhibition trials, but similarly, not during happy inhibition trials, compared with controls [84]. Together, these findings suggest that adolescent depression is associated with reduced activity in several neural regions when inhibiting responses to sad facial expressions.

Possibly because of the inconsistency of findings, no studies have investigated whether neural response patterns in youth depression comprise a risk marker.

\section{Summary}

Patterns of neural differences between adolescents with and without a history of depression (or low and high familial risk) are inconsistent across studies, possibly as adolescent depression is a heterogeneous condition, with different symptom dimensions associated with anomalies within the functioning of different neural circuits. Because studies tend to select samples on the basis of general depressive symptoms rather than one specific symptom dimension, this may attenuate any strong associations with neural anomalies that emerge during the performance of a cognitive task. Somewhat consistent with this interpretation, aggregated findings point to anomalies in several distributed but overlapping neural circuits. Future studies may wish to select on the basis of symptom dimensions such as anhedonia, poor working memory, rather than overall depression symptoms. To enable inferences on whether these neural anomalies explain reported biases in information processing (attention flexibility, interpretation biases, over-general memory), cognitive-affective tasks used during fMRI data acquisition need to be more carefully designed to isolate cognitive biases rather than generally affective-processing. One can tentatively speculate that neural abnormalities emerging from studies of cognitive reappraisal may explain biases in interpretation, but beyond this, it is difficult to directly attribute neural findings from emotion processing, reward processing and emotional inhibition to biases in voluntary attention deployment or memory biases and overgeneral memories. As with studies designed to measure information processing biases, tasks using affective stimuli that are 
more salient for young people may be more sensitive in assessing neural differences in relation to depression.

\section{Conclusions}

To summarise, there is reasonably consistent data to suggest that biases in attention, interpretation and memory characterise adolescents with depression, with some preliminary data suggesting that these could also comprise cognitive precursors of risk. Adolescent depression is also linked with dysfunctions within several distributed brain networks, but the precise involvement of these brain regions in precipitating symptoms, through biased information processing, is much less clear-cut. This places greater emphasis on interventions designed to target biased information processing. Consistent with this, there have been attempts to modify patterns of attention and interpretation biases through cognitive bias modification training techniques in depressed adolescents $[22,85]$. There have also been efforts to challenge OGM through therapeutic techniques aimed at increasing memory specificity in young people [86•]. Once the linkages between patterns of brain dysfunctions and adolescent depression are more clearly delineated, targeting these using neurofeedback training could be viable. Adult studies have shown the potential of fMRI-based neurofeedback in improving dysfunction in several neural regions, including the mPFC, amygdala and ventral striatum $[87,88]$ and we have recently demonstrated its feasibility in young people [89••], underscoring this as an important intervention for targeting neural abnormalities using cognitiveregulatory processes in adolescent depression.

\begin{abstract}
Acknowledgements This review includes independent research from a Clinical Doctoral Research Fellowship (Dr Victoria Pile, ICA-CDRF-2015-01-007) supported by the National Institute for Health Research and Health Education England. The views expressed in this publication are those of the authors and not necessarily those of the NHS, NIHR, Health Education England or the Department of Health.
\end{abstract}

\section{Compliance with Ethical Standards}

Conflict of Interest The authors declare that they have no conflict of interest.

Human and Animal Rights and Informed Consent This article does not contain any studies with human or animal subjects performed by any of the authors.

Open Access This article is distributed under the terms of the Creative Commons Attribution 4.0 International License (http:// creativecommons.org/licenses/by/4.0/), which permits unrestricted use, distribution, and reproduction in any medium, provided you give appropriate credit to the original author(s) and the source, provide a link to the Creative Commons license, and indicate if changes were made.

\section{References}

Papers of particular interest, published recently, have been highlighted as: • Of importance •• Of major importance

1. World Health Organisation. The global burden of disease: 2004 update. Geneva: WHO; 2008.

2. Blazer D, Kessler R, McGonagle K, Swartz M. The prevalence and distribution of major depression in a national community sample: the National Comorbidity Survey. Am J Psychiatry. 1994;151(7): 979-86.

3. Zisook S, Rush AJ, Lesser I, Wisniewski SR, Trivedi M, Husain MM, et al. Preadult onset vs. adult onset of major depressive disorder: a replication study. Acta Psychiatr Scand. 2007;115(3):196205. https://doi.org/10.1111/j.1600-0447.2006.00868.x.

4. Kessler RC. The costs of depression. Psychiatr Clin. 2012;35(1):114.

5. McLeod GFH, Horwood LJ, Fergusson DM. Adolescent depression, adult mental health and psychosocial outcomes at 30 and 35 years. Psychol Med. 2016;46(7):1401-12.

6. Mojtabai R, Olfson M, Han B. National trends in the prevalence and treatment of depression in adolescents and young adults. Pediatrics. 2016;138(6):e20161878.

7. Calear AL, Christensen H. Systematic review of school-based prevention and early intervention programs for depression. J Adolesc. 2010;33(3):429-38.

8. Hankin BL, Gibb BE, Abela JRZ, Flory K. Selective attention to affective stimuli and clinical depression among youths: role of anxiety and specificity of emotion. J Abnorm Psychol. 2010;119(3): 491-501. https://doi.org/10.1037/a0019609.

9. Platt B, Murphy SE, Lau JYF. The association between negative attention biases and symptoms of depression in a community sample of adolescents. PeerJ. 2015;3:e1372.

10. De Voogd EL, Wiers RW, Prins PJM, Salemink E. Visual search attentional bias modification reduced social phobia in adolescents. J Behav Ther Exp Psychiatry. 2014;45(2):252-9. https://doi.org/10. 1016/j.jbtep.2013.11.006.

11. Reid SC, Salmon K, Lovibond PF. Cognitive biases in childhood anxiety, depression, and aggression: are they pervasive or specific? Cogn Ther Res. 2006;30(5):531-49. https://doi.org/10.1007/ s10608-006-9077-y.

12. Osinsky R, Lösch A, Hennig J, Alexander N, MacLeod C. Attentional bias to negative information and 5-HTTLPR genotype interactively predict students' emotional reactivity to first university semester. Emotion. 2012;12(3):460-9.

13. Lonigan CJ, Vasey MW. Negative affectivity, effortful control, and attention to threat-relevant stimuli. J Abnorm Child Psychol. 2009;37(3):387-99. https://doi.org/10.1007/s10802-008-9284-y.

14. Harrison AJ, Gibb BE. Attentional biases in currently depressed children: an eye-tracking study of biases in sustained attention to emotional stimuli. J Clin Child Adolesc Psychol. 2015;44(6):100814. https://doi.org/10.1080/15374416.2014.930688.

15. Joormann J, Talbot L, Gotlib IH. Biased processing of emotional information in girls at risk for depression. J Abnorm Psychol. 2007;116(1):135-43. https://doi.org/10.1037/0021-843X.116.1. 135.

16. Kujawa AJ, Torpey D, Kim J, Hajcak G, Rose S, Gotlib IH, et al. Attentional biases for emotional faces in young children of mothers with chronic or recurrent depression. J Abnorm Child Psychol. 2011;39(1):125-35. https://doi.org/10.1007/s10802-010-9438-6.

17. Connell AM, Patton E, Klostermann S, Hughes-Scalise A. Attention bias in youth: associations with youth and mother's depressive symptoms moderated by emotion regulation and affective 
dynamics during family interactions. Cognit Emot. 2013;27(8): 1522-34. https://doi.org/10.1080/02699931.2013.803459.

18. Gibb BE, Benas JS, Grassia M, McGeary J. Children's attentional biases and 5-HTTLPR genotype: potential mechanisms linking mother and child depression. J Clin Child Adolesc Psychol. 2009;38(3):415-26.

19. Waters AM, Forrest K, Peters RM, Bradley BP, Mogg K. Attention bias to emotional information in children as a function of maternal emotional disorders and maternal attention biases. J Behav Ther Exp Psychiatry. 2015;46:158-63. https://doi.org/10.1016/j.jbtep. 2014.10.002.

20. Eley TC, Gregory AM, Lau JYF, McGuffin P, Napolitano M, Rijsdijk FV, et al. In the face of uncertainty: a twin study of ambiguous information, anxiety and depression in children. J Abnorm Child Psychol. 2008;36(1):55-65.

21. Orchard F, Pass L, Reynolds S. 'It Was All My Fault'; negative interpretation bias in depressed adolescents. J Abnorm Child Psychol. 2016;44(5):991-8. https://doi.org/10.1007/s10802-0150092-X.

22. Micco JA, Henin A, Hirshfeld-Becker DR. Efficacy of interpretation bias modification in depressed adolescents and young adults. Cogn Ther Res. 2014;38(2):89-102.

23. Dineen KA, Hadwin JA. Anxious and depressive symptoms and children's judgements of their own and others' interpretation of ambiguous social scenarios. J Anxiety Disord. 2004;18(4):499513. https://doi.org/10.1016/S0887-6185(03)00030-6.

24. Haller SP, Raeder SM, Scerif G, Kadosh KC, Lau JYF. Measuring online interpretations and attributions of social situations: links with adolescent social anxiety. J Behav Ther Exp Psychiatry. 2016;2016(50):250-6.

25. Rude SS, Wenzlaff RM, Gibbs B, Vane J, Whitney T. Negative processing biases predict subsequent depressive symptoms. Cognit Emot. 2002;16(3):423-40. https://doi.org/10.1080/ 02699930143000554.

26. Dearing KF, Gotlib IH. Interpretation of ambiguous information in girls at risk for depression. J Abnorm Child Psychol. 2009;37(1): 79-91. https://doi.org/10.1007/s10802-008-9259-z.

27. Wells TT, Vanderlind WM, Selby EA, Beevers CG. Childhood abuse and vulnerability to depression: cognitive scars in otherwise healthy young adults. Cognit Emot. 2014;28(5):821-33. https://doi. org/10.1080/02699931.2013.864258.

28. Platt B, Waters AM, Schulte-Koerne G, Engelmann L, Salemink E. A review of cognitive biases in youth depression: attention, interpretation and memory. Cognit Emot. 2017;31(3):462-83. https:// doi.org/10.1080/02699931.2015.1127215.

29. Neshat-Doost HT, Taghavi MR, Moradi AR, Yule W, Dalgleish T. Memory for emotional trait adjectives in clinically depressed youth. J Abnorm Psychol. 1998;107(4):642-50.

30. Zupan BA, Hammen C, Jaenicke C. The effects of current mood and prior depressive history on self-schematic processing in children. J Exp Child Psychol. 1987;43(1):149-58. https://doi.org/10. 1016/0022-0965(87)90056-7.

31. Dalgleish T, Taghavi R, Neshat-Doost H, Moradi A, Canterbury R, Yule W. Patterns of processing bias for emotional information across clinical disorders: a comparison of attention, memory, and prospective cognition in children and adolescents with depression, generalized anxiety, and posttraumatic stress disorder. J Clin Child Adolesc Psychol. 2003;32(1):10-21. https://doi.org/10.1207/ S15374424JCCP3201.

32. Gençöz T, Voelz ZR, Gençöz F, Pettit JW, Joiner TE. Specificity of information processing styles to depressive symptoms in youth psychiatric inpatients. J Abnorm Child Psychol. 2001;29(3):25562.

33. Timbremont B, Braet C, Bosmans G, Van Vlierberghe L. Cognitive biases in depressed and non-depressed referred youth. Clin Psychol Psychother. 2008;15(5):329-39. https://doi.org/10.1002/cpp.579.
34. Bishop S, Dalgleish T, Yule W. Memory for emotional stories in high and low depressed children. Memory. 2004;12(2):214-30.

35. Goldstein BL, Hayden EP, Klein DN. Stability of self-referent encoding task performance and associations with change in depressive symptoms from early to middle childhood. Cognit Emot. 2014;29(8):1445-55. https://doi.org/10.1080/02699931.2014. 990358.

36. Asarnow LD, Thompson RJ, Joormann J, Gotlib IH. Children at risk for depression: memory biases, self-schemas, and genotypic variation. J Affect Disord. 2014;159:66-72.

37. Conway MA, Pleydell-Pearce CW. The construction of autobiographical memories in the self-memory system. Psychol Rev. 2000;107(2):261-88.

38. Hitchcock C, Nixon RDV, Weber N. A review of overgeneral memory in child psychopathology. Br J Clin Psychol. 2014;53(2):170 93. https://doi.org/10.1111/bjc. 12034 This is a review of 17 studies examining overgeneralised memories (OGM) in youth depression, concluding that OGM does characterise the disorder in this age group.

39. Park RJ, Goodyer IM, Teasdale JD. Effects of induced rumination and distraction on mood and overgeneral autobiographical memory in adolescent major depressive disorder and controls. J Child Psychol Psychiatry Allied Discip. 2004;45(5):996-1006. https:// doi.org/10.1111/j.1469-7610.2004.t01-1-00291.x.

40. Rawal A, Rice F. Examining overgeneral autobiographical memory as a risk factor for adolescent depression. J Am Acad Child Adolesc Psychiatry. 2012;51(5):518-27. https://doi.org/10.1016/j.jaac. 2012.02.025.

41. Hipwell AE, Sapotichne B, Klostermann S, Battista D, Keenan K. Autobiographical memory as a predictor of depression vulnerability in girls. J Clin Child Adolesc Psychol. 2011;40(2):254-65. https:// doi.org/10.1080/15374416.2011.546037.Autobiographical.

42. Brennen T, Hasanović M, Zotović M, Blix I, Skar AS, Prelić NK et al. Trauma exposure in childhood impairs the ability to recall specific autobiographical memories in late adolescence. J Trauma Stress. 2010;23(2):240-7. https://doi.org/10.1002/jts.

43. Decker AD, Hermans D, Raes F, Eelen P, Decker AD, Hermans D, et al. Autobiographical memory specificity and trauma in inpatient adolescents and trauma in inpatient adolescents. J Clin Child Adolesc Psychol. 2003;32(1):22-31.

44. Nixon RDV, Ball S-A, Sterk J, Best T, Beatty L. Autobiographical memory in children and adolescents with acute stress and chronic posttraumatic stress disorder. Behav Chang. 2013;30(3):180-98. https://doi.org/10.1017/bec.2013.17.

45. Anderson P. Assessment and development of executive function (EF) during childhood. Child Neuropsychology. 2002;8(2):71-82.

46. Gotlib IH, Joormann J. Cognition and depression: current status and future directions. Annu Rev Clin Psychol. 2010;6:285-312.

47. Vilgis V, Silk TJ, Vance A. Executive function and attention in children and adolescents with depressive disorders: a systematic review. Eur Child Adolesc Psychiatry. 2015;24(4):365-84. https:// doi.org/10.1007/s00787-015-0675-7 This systematic review examines 33 studies of executive function in youth depression, concluding that there is little support for a executive function defecits in this group.

48. Holler K, Kavanaugh B, Cook NE. Executive functioning in adolescent depressive disorders. J Child Fam Stud. 2014;23(8):131524.

49. van Deurzen PA, Buitelaar JK, Brunnekreef JA, Ormel J, Minderaa RB, Hartman CA, et al. Response time variability and response inhibition predict affective problems in adolescent girls, not in boys: the TRAILS study. Eur Child Adolesc Psychiatry. 2012;21(5):27787.

50. Kyte ZA, Goodyer IM, Sahakian BJ. Selected executive skills in adolescents with recent first episode major depression. J Child 
Psychol Psychiatry Allied Discip. 2005;46(9):995-1005. https:// doi.org/10.1111/j.1469-7610.2004.00400.x.

51. Ladouceur CD, Dahl RE, Williamson DE, Birmaher B, Axelson DA, Ryan ND, et al. Processing emotional facial expressions influences performance on a Go/NoGo task in pediatric anxiety and depression. J Child Psychol Psychiatry Allied Discip. 2006;47(11):1107-15. https://doi.org/10.1111/j.1469-7610.2006. 01640.x.

52. Maalouf FT, Clark L, Tavitian L, Sahakian BJ, Brent D, Phillips ML. Bias to negative emotions: a depression state-dependent marker in adolescent major depressive disorder. Psychiatry Res. 2012;198(1):28-33. https://doi.org/10.1016/j.psychres.2012.01. 030.

53. Rogers MA, Kasai K, Koji M, Fukuda R, Iwanami A, Nakagome $\mathrm{K}$, et al. Executive and prefrontal dysfunction in unipolar depression: a review of neuropsychological and imaging evidence. Neurosci Res. 2004;50(1):1-11.

54. Stuhrmann A, Suslow T, Dannlowski U. Facial emotion processing in major depression: a systematic review of neuroimaging findings. Biol Mood Anxiety Disord. 2011;1(1):10.

55. Fuhrmann D, Knoll LJ, Blakemore SJ. Adolescence as a sensitive period of brain development. Trends Cogn Sci. 2015;19(10):55866.

56. Vijayakumar N, Allen NB, Youssef G, Dennison M, Yücel M, Simmons JG, et al. Brain development during adolescence: a mixed-longitudinal investigation of cortical thickness, surface area, and volume. Hum Brain Mapp. 2016;37(6):2027-38.

$57 . \bullet$ Kerestes R, Davey CG, Stephanou K, Whittle S, Harrison BJ. Functional brain imaging studies of youth depression: a systematic review. Neuroimage Clin. 2014;4:209-31 This is a systematic review of 20 adolescent depression fMRI studies conducted up to 2014. Highlights dysfunction in the amygdala and vmPFC.

58.• Miller CH, Hamilton JP, Sacchet MD, Gotlib IH. Meta-analysis of functional neuroimaging of major depressive disorder in youth. JAMA Psychiatry. 2015;72(10):1045-53 This is a meta-analysis of 14 adolescent depression fMRI studies conducted up to 2015. Highlights abnormalities in regions including the dIPFC, ACC, insula, thalamus and caudate.

59. Redlich R, Opel N, Bürger C, Dohm K, Grotegerd D, Förster K, et al. The limbic system in youth depression: brain structural and functional alterations in adolescent in-patients with severe depression. Neuropsychopharmacology. 2018;43:546-54.

60. Henderson SE, Vallejo AI, Ely BA, Kang G, Roy AK, Pine DS, et al. The neural correlates of emotional face-processing in adolescent depression: a dimensional approach focusing on anhedonia and illness severity. Psychiatry Res Neuroimaging. 2014;224(3): 234-41.

61. van den Bulk BG, Meens PH, van Lang ND, De Voogd EL, van der Wee NJ, Rombouts SA, et al. Amygdala activation during emotional face processing in adolescents with affective disorders: the role of underlying depression and anxiety symptoms. Front Hum Neurosci. 2014;8:393.

62. Chan SW, Sussmann JE, Romaniuk L, Stewart T, Lawrie SM, Hall $\mathrm{J}$, et al. Deactivation in anterior cingulate cortex during facial processing in young individuals with high familial risk and early development of depression: fMRI findings from the Scottish Bipolar Family Study. J Child Psychol Psychiatry. 2016;57(11):1277-86.

63. Ho TC, Yang G, Wu J, Cassey P, Brown SD, Hoang N, et al. Functional connectivity of negative emotional processing in adolescent depression. J Affect Disord. 2014;155:65-74.

64. Ho TC, Connolly CG, Blom EH, LeWinn KZ, Strigo IA, Paulus MP, et al. Emotion-dependent functional connectivity of the default mode network in adolescent depression. Biol Psychiatry. 2015;78(9):635-46.

65. Chai XJ, Hirshfeld-Becker D, Biederman J, Uchida M, Doehrmann $\mathrm{O}$, Leonard JA, et al. Functional and structural brain correlates of risk for major depression in children with familial depression. Neuroimage Clin. 2015;8:398-407.

66. Swartz JR, Williamson DE, Hariri AR. Developmental change in amygdala reactivity during adolescence: effects of family history of depression and stressful life events. Am J Psychiatr. 2015;172(3): 276-83 This study demonstrates complex interactions between familial risk and life stress with age on amygdala reactivity to threat, which may represent different mechanisms underlying vulnerability to depression.

67. Burkhouse KL, Kujawa A, Keenan K, Klumpp H, Fitzgerald KD, Monk CS, et al. The relation between parent depressive symptoms and neural correlates of attentional control in offspring: a preliminary study. Psychiatry Res Neuroimaging. 2017;263:26-31.

68. Belden AC, Pagliaccio D, Murphy ER, Luby JL, Barch DM. Neural activation during cognitive emotion regulation in previously depressed compared to healthy children: evidence of specific alterations. J Am Acad Child Adolesc Psychiatry. 2015;54(9):771-81.

69. LeWinn KZ, Strigo IA, Connolly CG, Ho TC, Tymofiyeva O, Sacchet MD, et al. An exploratory examination of reappraisal success in depressed adolescents: preliminary evidence of functional differences in cognitive control brain regions. J Affect Disord. 2018;240:155-64.

70. Platt B, Campbell CA, James AC, Murphy SE, Cooper MJ, Lau JYF. Cognitive reappraisal of peer rejection in depressed versus non-depressed adolescents: functional connectivity differences. J Psychiatr Res. 2015;61:73-80.

71. Stephanou K, Davey CG, Kerestes R, Whittle S, Harrison BJ. Hard to look on the bright side: neural correlates of impaired emotion regulation in depressed youth. Soc Cogn Affect Neurosci. 2017;12(7):1138-48.

72. Murphy ER, Barch DM, Pagliaccio D, Luby JL, Belden AC. Functional connectivity of the amygdala and subgenual cingulate during cognitive reappraisal of emotions in children with MDD history is associated with rumination. Dev Cogn Neurosci. 2016;18:89-100.

73. Stringaris A, Vidal-Ribas Belil P, Artiges E, Lemaitre H, GollierBriant $\mathrm{F}$, Wolke $\mathrm{S}$, et al. The brain's response to reward anticipation and depression in adolescence: dimensionality, specificity, and longitudinal predictions in a community-based sample. Am J Psychiatr. 2015;172(12):1215-23.

74. Insel C, Glenn CR, Nock MK, Somerville LH. Aberrant striatal tracking of reward magnitude in youth with current or past-year depression. J Abnorm Psychol. 2019;128(1):44-56.

75. Rzepa E, Fisk J, McCabe C. Blunted neural response to anticipation, effort and consummation of reward and aversion in adolescents with depression symptomatology. J Psychopharmacol. 2017;31(3):303-11

76. Jin J, Narayanan A, Perlman G, Luking K, DeLorenzo C, Hajcak G, et al. Orbitofrontal cortex activity and connectivity predict future depression symptoms in adolescence. Biol Psychiatry Cogn Neurosci Neuroimaging. 2017;2(7):610-8.

77. Morgan JK, Shaw DS, Olino TM, Musselman SC, Kurapati NT, Forbes EE. History of depression and frontostriatal connectivity during reward processing in late adolescent boys. J Clin Child Adolesc Psychol. 2016;45(1):59-68.

78. Sharp C, Kim S, Herman L, Pane H, Reuter T, Strathearn L. Major depression in mothers predicts reduced ventral striatum activation in adolescent female offspring with and without depression. J Abnorm Psychol. 2014;123(2):298-309.

79. Olino TM, McMakin DL, Morgan JK, Silk JS, Birmaher B, Axelson DA, et al. Reduced reward anticipation in youth at highrisk for unipolar depression: a preliminary study. Dev Cogn Neurosci. 2014;8:55-64.

80. Qu Y, Fuligni AJ, Galván A, Lieberman MD, Telzer EH. Links between parental depression and longitudinal changes in youths' 
neural sensitivity to rewards. Soc Cogn Affect Neurosci. 2016;11(8):1262-71.

81. Diler RS, Pan LA, Segreti A, Ladouceur CD, Forbes E, Cela SR, et al. Differential anterior cingulate activity during response inhibition in depressed adolescents with bipolar and unipolar major depressive disorder. J Can Acad Child Adolesc Psychiatry. 2014;23(1): 10

82. Ho TC, Sacchet MD, Connolly CG, Margulies DS, Tymofiyeva O, Paulus MP, et al. Inflexible functional connectivity of the dorsal anterior cingulate cortex in adolescent major depressive disorder. Neuropsychopharmacology. 2017;42(12):2434-45.

83. Chuang JY, Hagan CC, Murray GK, Graham J, Ooi C, Tait R, et al. Adolescent major depressive disorder: neuroimaging evidence of sex difference during an affective go/no-go task. Front Psychiatry. 2017;8:119.

84. Colich NL, Foland-Ross LC, Eggleston C, Singh MK, Gotlib IH. Neural aspects of inhibition following emotional primes in depressed adolescents. J Clin Child Adolesc Psychol. 2016;45(1): 21-30.

85. Yang W, Zhang JX, Ding Z, Xiao L. Attention bias modification treatment for adolescents with major depression: a randomized controlled trial. J Am Acad Child Adolesc Psychiatry. 2016;55(3):20818.

86. Pile V, Smith P, Leamy M, Blackwell SE, Meiser-Stedman R, Stringer D, et al. A brief early intervention for adolescent depression that targets emotional mental images and memories: protocol for a feasibility randomised controlled trial (IMAGINE trial). Pilot and Feasibility Studies. 2018;4(1):97 This describes the trial protocol for a novel intervention designed to increase memory specificity among depressed adolescents.

87. Johnston SJ, Boehm SG, Healy D, Goebel R, Linden DE. Neurofeedback: a promising tool for the self-regulation of emotion networks. Neuroimage. 2010;49:1066-72.

88. Koush Y, Meskaldji DE, Pichon S, Rey G, Rieger SW, Linden DE, et al. Learning control over emotion networks through connectivitybased neurofeedback. Cereb Cortex. 2015;27:1193-202.

89. • Kadosh KC, Luo Q, de Burca C, Sokunbi MO, Feng J, Linden DE, et al. Using real-time fMRI to influence effective connectivity in the developing emotion regulation network. Neuroimage. 2016;125: 616-26 This demonstrates the suitability of real-time fMRIbased neurofeedback to influence developing emotion regulation in adolescents and thus its potential as a depression intervention among youths.

Publisher's Note Springer Nature remains neutral with regard to jurisdictional claims in published maps and institutional affiliations. 